\title{
Spinocerebellar ataxia type 8
}

INSERM

\section{Source}

INSERM. (1999). Orphanet: an online rare disease and orphan drug data base.

Spinocerebellar ataxia type 8. ORPHA:98760

Spinocerebellar ataxia type 8 (SCA8) is a subtype of type I autosomal dominant cerebellar ataxia (ADCA type I; see this term) characterized by cerebellar ataxia and cog nitive dysfunction in almost three quarters of patients and pyramidal and sensory signs in approximately a third of patients. 